\title{
RefORMA PSIQUiátricA EM NATAL-RN: EVOLUÇÃo HiSTÓRICA E OS DESAFIOS DA ASSISTÊNCIA DE ENFERMAGEM
}

\author{
Fernando de Souza Silva \\ Clélia Albino Simpson ${ }^{2}$ \\ Rita de Cássia Dantas ${ }^{3}$
}

\begin{abstract}
Este estudo objetivou discorrer sobre a evolução das práticas assistenciais ao portador de transtornos psiquiátricos na cidade de Natal $(\mathrm{RN})$, por meio de uma revisão integrativa em que encontramos seis pesquisas sobre a temática. Acreditamos que as reflexões propostas subsidiam mudanças assistenciais à enfermagem em saúde mental. Dentre as conclusões percebemos que a necessidade de maior capacitação dos enfermeiros em saúde mental alicerça-se na exigência desse profissional em favorecer a integração de ações que promovam a efetivação das transformações práticas, saberes e valores culturais, impregnados no cuidado cotidiano aos clientes e seus familiares.
\end{abstract}

Descritores: Enfermagem/história; Psiquiatria; Saúde Mental; Cuidados de Enfermagem.

\footnotetext{
${ }^{1}$ Enfermeiro, Hospital Universitário Onofre Lopes, Natal, RN, Brasil. Doutorando, Universidade Federal do Rio Grande do Norte, Natal, RN, Brasil.

2 PhD, Professor Associado, Universidade Federal do Rio Grande do Norte, Natal, RN, Brasil.

${ }^{3}$ MSc, Enfermeira, Secretaria Municipal de Saúde, Natal, RN, Brasil.
} 


\section{Psychiatric Reform in Natal-RN: historical Evolution AND the CHALLENGES OF NURSING CARE}

The purpose of this study is to discuss the evolution of care practices of patients with psychiatric disorders in the city of Natal $(\mathrm{RN})$, through an integrative review in which we found six studies on the subject. We believe that the ideas proposed promote changes in mental health nursing care. Among the conclusions we realized the need for better training of mental health nurses, requiring these professionals to support integration of care in order to promote the transformation of practices, knowledge and cultural values, impregnated in the routine care of clients and their families.

Descriptors: Nursing/history; Psychiatry; Mental Health; Nursing Care.

\section{REFORMA PSIQUiÁTRICA EN NATAL-RN: EVOLUCIÓN HISTÓRICA Y LOS DESAFÍOS DE LA ASISTENCIA DE ENFERMERÍA}

Este estudio tiene como objetivo reflexionar sobre la evolución de las prácticas asistenciales al portador de trastornos psiquiátricos en la ciudad de Natal (RN), por medio de una revisión integradora en que encontramos seis investigaciones sobre la temática. Creemos que las reflexiones propuestas contribuyen a los cambios asistenciales de la enfermería en la salud mental. De entre las conclusiones percibimos que la necesidad de mayor capacitación de los enfermeros en salud mental se basa en la exigencia de ese profesional en favorecer la integración de acciones que promuevan la efectividad de las transformaciones prácticas, saberes y valores culturales, impregnados en el cuidado cotidiano a los enfermos y a sus familiares.

Descriptores: Enfermería/historia; Psiquiatría; Salud Mental; Atención de Enfermería.

\section{Introdução}

Historicamente, foi imputada aos hospitais psiquiátricos a missão de excluir do meio social as pessoas portadoras de sofrimento psíquico, fomentada pela marginalização, estigma e preconceito, justificada pelo objetivo de reabilitar e reintegrar os doentes às dinâmicas sociais mais democráticas; entretanto, esse discurso se encerra entre os muros dessas instituições asilares, nas práticas indignas e desumanas empregadas, nas péssimas condições estruturais e de assistência, em precárias possibilidades terapêuticas e na ausência de políticas favoráveis provindas das esferas de gestão em saúde.
Como uma proposta contra hegemônica, a reforma psiquiátrica surge no Brasil com o intuito de melhorar a qualidade de vida dos pacientes portadores de sofrimento psíquico, resgatando sua cidadania e liberdade, por meio da promoção de uma assistência à saúde mental eficiente, eficaz e humanizada, por meio da redução das internações manicomiais, participação da família como corresponsável na reabilitação e reintegração social, associada à expansão e às melhorias no atendimento ambulatorial, além da reavaliação das práticas profissionais.

O Rio Grande do Norte é um dos estados pioneiros na implantação da reforma psiquiátrica brasileira, tendo sido local de grandes mudanças na assistência aos pacientes portadores de sofrimento psíquico, inserido no 
movimento contraditório às internações manicomiais e favorecendo a ampliação dos cuidados extra-hospitalares ${ }^{(1)}$.

O processo de reforma psiquiátrica no Rio Grande do Norte, em especial na capital Natal$\mathrm{RN}$, propõe a integração de esforços dos profissionais e gestores da saúde pública e a coparticipação das famílias dos pacientes, com vistas a promover condições favoráveis às boas práticas em psiquiatria ofertadas nas unidades de assistência e apoio em saúde mental ${ }^{(1)}$.

Novas perspectivas assistenciais são exigidas dos profissionais da saúde mental, ante as propostas da reforma psiquiátrica, e de sobremaneira os cuidados de enfermagem, inserida nesse contexto como agente de transformação social, mantenedora do bem-estar, reabilitação e reintegração dos pacientes, destarte, a maior compreensão do contexto da assistência psiquiátrica oferecida à população é necessária para a reformulação do cuidar.

Este estudo se justifica pelo fato de o Rio Grande do Norte ser um dos estados pioneiros no movimento de reforma psiquiátrica brasileira ${ }^{(1)} \mathrm{e}$, desta maneira, a capital Natal é boa referência para embasar discussões acerca da evolução das práticas em saúde mental, possibilitando, consequentemente, melhor entendimento da atual conjuntura de assistência, tendendo a promover reflexões sobre a otimização e adequações do tratamento aos enfermos mentais, contexto em que a enfermagem encontra-se inserida e empenhada a prestar os cuidados demandados dessa clientela, ante as atuais exigências legais, técnicas e humanísticas.

Dessa maneira, objetivamos discorrer sobre a evolução das práticas assistenciais de enfermagem ao portador de transtornos psiquiátricos na cidade de Natal, por meio de uma revisão integrativa sobre a temática. Acreditamos que um melhor entendimento do contexto atual de reformulações estruturais e do cuidado subsidie a construção de propostas de ações capazes de melhorar a assistência, mais especificamente a de enfermagem em saúde mental.

\section{Métodos}

O presente estudo constitui-se de um fragmento da dissertação de mestrado do Programa de pós-graduação em enfermagem do Departamento de enfermagem da Universidade Federal do Rio Grande do Norte, intitulada: Histórias de vidas de usuários de psicofármacos: o desafio do cuidar para a enfermagem. Aprovado pelo Comitê de Ética em Pesquisa da Universidade Federal do Rio Grande do Norte sob o protocolo 198/2009.

Neste estudo, realizou-se uma revisão integrativa da literatura, com o intuito de investigar quais as produções científicas publicadas sobre a temática dos cuidados de enfermagem ao portador de transtornos psiquiátricos, no contexto histórico e atual de reformulação da assistência em saúde mental, em especial no Estado do Rio Grande do Norte.

Optou-se por utilizar a revisão integrativa devido ao seu potencial de síntese, categorização, análise e avaliação do conhecimento científico já produzido sobre uma dada temática ${ }^{(2)}$; dessa maneira, constitui-se do método adequado para alcançar os objetivos propostos por este estudo.

A síntese viabiliza a contextualização acerca da temática e sinaliza as lacunas que precisam ser preenchidas com novos estudos, contribuindo para discussões a respeito dos métodos e resultados de pesquisas anteriores publicadas ${ }^{(2)}$; dessa maneira, realizou-se uma busca nas bases de dados e pesquisa da Biblioteca Virtual em Saúde (BVS), Lilacs e Medline, entre os anos de 2007 e 2012. A escolha por essas bases de dados deve-se ao fato de estas englobarem publicações nacionais e internacionais de grande impacto.

O período temporal de busca dos artigos foi de março a junho de 2012, em que se utilizou, de forma combinada e aleatória, as palavras chave, presentes entre os Descritores DeCs, "História", "Psiquiatria", "Enfermagem" e "Saúde Mental".

Os critérios de inclusão dos artigos foram aqueles que discorreram sobre o processo de reforma psiquiátrica no Brasil e no Estado do Rio Grande do Norte, abordando a enfermagem e a saúde mental neste contexto de construção e reformulação. Foram incluídos os estudos publicados nas bases de dados e pesquisa, com até cinco anos de publicação, nos idiomas português, inglês e espanhol. Para verificar se os artigos atendiam aos critérios de inclusão, realizou-se uma avaliação por dois revisores independentes, através da leitura preliminar dos resumos e, posteriormente, dos manuscritos integralmente.

Os artigos encontrados foram organizados nas categorias título, objetivos, resultados, principais conclusões e as referências de cada estudo, com o intuito de sumarizar as informações de maneira concisa, formando um banco de dados de fácil acesso e manejo. 


\section{Resultados}

A busca nas bases de dados e pesquisa evidenciou o total de doze artigos com a utilização dos descritores; entretanto, ao submetê-los aos critérios de inclusão deste estudo, foram selecionados seis artigos que promoveram debates sobre a temática específica, destes, dois publicados no ano de 2011, dois em 2010, um em 2009 e outro em 2007.
A Figura 1 apresenta a relação de trabalhos publicados sobre o processo de reforma psiquiátrica, em especial na cidade de Natal$\mathrm{RN}$, em que a enfermagem encontra-se inserida no contexto de assistência ao portador de sofrimento mental, evidenciando um quantitativo insipiente de estudos na área da enfermagem psiquiátrica no Estado do Rio Grande do Norte.

\begin{tabular}{|c|c|c|c|c|}
\hline Título & Objetivo & Resultados & Conclusões & Referência \\
\hline $\begin{array}{l}\text { O fenômeno da } \\
\text { reinternação: um } \\
\text { desafio à reforma } \\
\text { psiquiátrica. }\end{array}$ & $\begin{array}{l}\text { Avaliar as reinterna- } \\
\text { ções no Hospital Dr. } \\
\text { João Machado em } \\
\text { Natal-RN, bem como } \\
\text { identificar os efeitos da } \\
\text { proposta de alta assis- } \\
\text { tida desse hospital. }\end{array}$ & $\begin{array}{l}\text { O grande número de pacientes, a au- } \\
\text { sência de profissionais qualificados e } \\
\text { engajados com as propostas da rein- } \\
\text { serção social; a falta de uma articula- } \\
\text { ção com a rede de atenção à saúde em } \\
\text { geral; a prática da alta-assistida está } \\
\text { fragmentada. }\end{array}$ & $\begin{array}{l}\text { Constatou-se que o projeto enfrenta } \\
\text { alguns entraves e que a estratégia de } \\
\text { dar assistência após a alta hospitalar, } \\
\text { garantindo uma atenção continuada } \\
\text { e inserida no meio social e familiar, é } \\
\text { fundamental na tentativa de evitar a } \\
\text { reinternação. }\end{array}$ & $\begin{array}{l}\text { Mental, ano IX-no16, } \\
\text { Barbacena-MG, -jan./ } \\
\text { jun.2011. p. 417-442. }\end{array}$ \\
\hline $\begin{array}{l}\text { Extinção de um } \\
\text { serviço psiquiátrico } \\
\text { intermediário e as } \\
\text { repercussões na } \\
\text { atenção à saúde } \\
\text { mental. }\end{array}$ & $\begin{array}{l}\text { Registrar o fenômeno } \\
\text { de extinção de um ser- } \\
\text { viço psiquiátrico inter- } \\
\text { mediário, os possíveis } \\
\text { fatores que o determi- } \\
\text { naram e as principais } \\
\text { repercussões para a } \\
\text { rede de atenção à saú- } \\
\text { de mental local. }\end{array}$ & $\begin{array}{l}\text { Os dados foram interpretados a partir } \\
\text { dos quatro níveis de camadas: A extin- } \\
\text { ção do HD (contexto imediato); O HD e } \\
\text { a realidade local de Atenção à Saúde } \\
\text { Mental (contexto específico); Valores e } \\
\text { crenças atribuídos aos serviços inter- } \\
\text { mediários (contexto geral); e políticas- } \\
\text { ligadas ao HD e os serviços intermediá- } \\
\text { rios no Brasil (metacontexto). }\end{array}$ & $\begin{array}{l}\text { Após a extinção do Hospital-Dia, em } \\
2006 \text {, os usuários portadores de trans- } \\
\text { tornos mentais e seus familiares foram } \\
\text { orientados a buscar a continuidade do } \\
\text { tratamento na rede de saúde mental } \\
\text { municipal, que enfrenta contínuas difi- } \\
\text { culdades, como escassez de serviços e } \\
\text { falta de articulação com a rede básica } \\
\text { de saúde, além do próprio estigma e } \\
\text { preconceito social. }\end{array}$ & $\begin{array}{l}\text { CiencCuidSaude } \\
\text { 2011 Jul./Set.; 10(3): } \\
\text { 578-584. }\end{array}$ \\
\hline $\begin{array}{l}\text { Percepção de alunos } \\
\text { de graduação em } \\
\text { enfermagem sobre o } \\
\text { processo de reforma } \\
\text { psiquiátrica no Brasil }\end{array}$ & $\begin{array}{l}\text { Analisar a percepção } \\
\text { dos alunos do cur- } \\
\text { so de graduação em } \\
\text { enfermagem sobre o } \\
\text { processo de reforma } \\
\text { psiquiátrica no Brasil }\end{array}$ & $\begin{array}{l}\text { Os resultados mostraram que } 71 \% \text { dos } \\
\text { discentes reconhecem os direitos de } \\
\text { cidadão do portador de transtorno men- } \\
\text { tal, } 98 \% \text { entendem a necessidade do } \\
\text { suporte à família no cuidado a esse in- } \\
\text { divíduo e } 84 \% \text { avaliam a reforma psiqui- } \\
\text { átrica como contribuidora para melhoria } \\
\text { dos serviços de saúde mental. }\end{array}$ & $\begin{array}{l}\text { A percepção de alunos de graduação } \\
\text { em enfermagem apontaram a existên- } \\
\text { cia de fatores que influenciam a recu- } \\
\text { peração e socialização do portador } \\
\text { de transtorno mental, bem como seu } \\
\text { acompanhamento por parte da equipe } \\
\text { de saúde e da família. Os pontos indi- } \\
\text { caram uma importante estratégia para } \\
\text { reordenação da prática assistencial. }\end{array}$ & $\begin{array}{l}\text { Rev. Enferm. UERJ, } \\
\text { Rio de Janeiro, Abr/ } \\
\text { jun.2010; 18(2):235- } \\
40 .\end{array}$ \\
\hline $\begin{array}{l}\text { Fragmentos } \\
\text { históricos da } \\
\text { assistência } \\
\text { psiquiátrica no Rio } \\
\text { Grande do Norte- } \\
\text { Brasil. }\end{array}$ & $\begin{array}{l}\text { Resgatar aspectos do } \\
\text { funcionamento tera- } \\
\text { pêutico do Hospital-Dia } \\
\text { (HD) Dr. Élger Nunes } \\
\text { em Natal, Rio Grande } \\
\text { do Norte e analisar os } \\
\text { resultados referentes } \\
\text { ao número de usuá- } \\
\text { rios atendido de 1997- } \\
2004 \text {. }\end{array}$ & $\begin{array}{l}\text { Os resultados constataram uma maior } \\
\text { acessibilidade à modalidade de trata- } \\
\text { mento, diminuição no tempo de perma- } \\
\text { nência e melhoria das condições de alta } \\
\text { dos usuários com redução no número } \\
\text { de interrupções no tratamento. Salienta } \\
\text { a importância do Hospital-Dia (HD) no } \\
\text { processo de reforma psiquiátrica. }\end{array}$ & $\begin{array}{l}\text { Destaca-se a importância desse estudo } \\
\text { para todos da sociedade em geral, uma } \\
\text { vez que foram observadas as melhorias } \\
\text { advindas da terapêutica utilizada no HD } \\
\text { em relação ao tempo de permanência } \\
\text { dos pacientes com transtorno mental, } \\
\text { bem como as condições de alta desses } \\
\text { que, em sua maioria, estavam relacio- } \\
\text { nadas ao quadro de melhora clínica do } \\
\text { usuário. }\end{array}$ & $\begin{array}{l}\text { Rev. Gaúcha enferm. } \\
\text { Porto Alegre (RS), } \\
2010 \text { set.; } 31(3): \\
475-82 . \\
\end{array}$ \\
\hline $\begin{array}{l}\text { O apoio matricial } \\
\text { em unidades de } \\
\text { saúde da família: } \\
\text { experimentando } \\
\text { inovações em saúde } \\
\text { mental }\end{array}$ & $\begin{array}{l}\text { Discutir a percepção } \\
\text { dos técnicos das uni- } \\
\text { dades de saúde da } \\
\text { família do município } \\
\text { de Natal-Rn, acerca } \\
\text { da proposta de apoio } \\
\text { matricial nas referidas } \\
\text { unidades. }\end{array}$ & $\begin{array}{l}\text { A partir dos resultados observamos que } \\
\text { não há clareza acerca da proposta de } \\
\text { Apoio Matricial (AM) e há uma forte de- } \\
\text { manda cotidiana de } \\
\text { saúde mental não acolhida, pois os pro- } \\
\text { fissionais não } \\
\text { se sentem capacitados para tal e indi- } \\
\text { cam a necessidade de apoio e instru- } \\
\text { mentalização nesse campo }\end{array}$ & $\begin{array}{l}\text { Percebe-se a predominância do para- } \\
\text { digma biomédico na atenção à saúde, } \\
\text { em que se privilegiam os cuidados me- } \\
\text { dicamentosos na resolução dos proble- } \\
\text { mas de saúde da população, } \\
\text { como a prescrição indiscriminada de } \\
\text { psicotrópicos. É frequente a visão pre- } \\
\text { dominantemente fragmentada do tra- } \\
\text { balho em } \\
\text { saúde. }\end{array}$ & $\begin{array}{l}\text { Saúde Soc. São } \\
\text { Paulo, 2009. v. 18, n. } \\
\text { 1, p. 63-74. }\end{array}$ \\
\hline $\begin{array}{l}\text { Em defesa da } \\
\text { reforma psiquiátrica: } \\
\text { por um amanhã que } \\
\text { há de nascer sem } \\
\text { pedir licença. }\end{array}$ & $\begin{array}{l}\text { Realizar análise do } \\
\text { processo de reforma } \\
\text { psiquiátrica no Rio } \\
\text { Grande do Norte, com } \\
\text { vista à ressocialização } \\
\text { do portador de distúr- } \\
\text { bios mentais. }\end{array}$ & $\begin{array}{l}\text { Observou-se a presença de dois cam- } \\
\text { pos distintos de problemas: (1) crises } \\
\text { internas e específicas dos serviços e } \\
\text { de sua equipe de profissionais; proble- } \\
\text { mas institucionais e divergências teóri- } \\
\text { cas; (2) influências externas advindas } \\
\text { de interesses político-financeiros e de } \\
\text { uma cultura manicomial instalada nas } \\
\text { mentes tanto de profissionais quanto de } \\
\text { leigos que estavam fora das discussões } \\
\text { da reforma. }\end{array}$ & $\begin{array}{l}\text { A reforma psiquiátrica em Natal-RN su- } \\
\text { bordina-se à vontade política dos ges- } \\
\text { tores de saúde e aos rumos da econo- } \\
\text { mia brasileira. O movimento de reforma } \\
\text { psiquiátrica no estado esqueceu-se de } \\
\text { fazer novas construções teóricas e ope- } \\
\text { racionais, no plano de assistência em } \\
\text { saúde mental. A promoção à saúde, a } \\
\text { integração de práticas e a participação } \\
\text { social devem estar presentes na nova } \\
\text { agenda de saúde mental. }\end{array}$ & $\begin{array}{l}\text { História, ciências e } \\
\text { saúde. Manguinhos, } \\
\text { Rio de Janeiro, } 2007 . \\
\text { V. 14, n. 2, p. 549- } \\
\text { 569. Abr./jun. } \\
\\
\end{array}$ \\
\hline
\end{tabular}

Figura 1 - Levantamento das produções publicadas nas bases de dados e pesquisa, Natal-RN, Brasil, 2012. 
Os primórdios da assistência psiquiátrica e sua evolução

O processo de reforma psiquiátrica no Brasil teve início em 1970, constituindo-se na luta em defesa da melhor qualidade de assistência em saúde mental, com intuito de transformar o modelo de psiquiatria hospitalocêntrica asilar vigente. Nascido num período de exigências de profundas mudanças políticas que apontavam para a redemocratização do país, concomitante ao movimento sanitarista, alicerçado no desejo em reformular as relações de usuários dos serviços de saúde e os promovedores de cuidados ${ }^{(3)}$.

Os primórdios da psiquiatria potiguar se inserem na construção, em 1857, de um hospital Lazareto, caracterizado como uma instituição destinada ao depósito de leprosos, porém, o Lazareto não possuía especificidade, comumente atendia as pessoas portadoras de patologias que a sociedade estigmatizava e rotulava de escória social; assim, os casos tidos incuráveis, como a tuberculose, sífilis, varíola e aqueles com transtornos psiquiátricos, eram assistidos ali ${ }^{(3-4)}$.

No Lazareto, os pacientes com transtornos psiquiátricos eram submetidos a uma condição humilhante e desumana, amontoados e expostos nus ou acorrentados. Jovens, idosos, homens, mulheres e crianças sofriam maus-tratos e raramente voltavam ao convívio social. De certo, a instituição funcionava para garantir a reclusão compulsória de loucos, excluindo da sociedade os que apresentavam condutas de convivência tidas perigosas $^{(5)}$.

Em 1882, o Lazareto passa a ser chamado de Lazareto da Piedade de Natal, funcionando ainda sem condutas terapêuticas apropriadas para a reintegração dos pacientes à sociedade, mas com a função restrita de retirar das ruas os segregados. Em 1911, o Lazareto da Piedade de Natal passa a se chamar Asilo da Piedade, mas com a mesma configuração execrável de amontoar a "escória" social, termo abominável e estigmatizante ${ }^{(5-6)}$.

Em 1916, atua no Asilo da Piedade o médico Varela Santiago, que, apesar de não ser psiquiatra, passa a perceber o portador de transtorno mental como um doente que precisa de assistência a saúde, porém as condutas médicas da época não eram resolutivas e só aumentavam o sofrimento e os maus-tratos às pessoas internadas. $\mathrm{O}$ isolamento em espaços confinados, a contenção física com camisa-de-força e os abscessos de fixação causadores de infecções graves eram as opções terapêuticas $^{(7)}$.

$\mathrm{Na}$ direção do médico Varela Santiago, em 1921 o Asilo da Piedade passa a se chamar Hospital dos Alienados de Natal, utilizando o mesmo prédio, as mesmas instalações e a continuidade dos tratamentos humilhantes e degradantes dos internos. A denominação mudou nos anos idos, mas a intencionalidade do local perdurou, com confinamento, segregação, maus-tratos e a morte dos pacientes como resultado final de suas trajetórias de vida ${ }^{(3-4)}$.

Em 1936, retorna a Natal o recém-laureado em Medicina, o médico-psiquiatra João da Costa Machado, formado e influenciado pelos ideais revolucionários do professor de psiquiatria Dr. Ulysses Pernambucano, que propôs uma ruptura com os antigos métodos de assistência ao doente mental, incentivando a ressocialização e humanização como focos primordiais da terapêutica psiquiátrica $^{(3,5)}$.

O Dr. João da Costa Machado propôs uma revolução no atendimento psiquiátrico no estado do Rio Grande do Norte, defendendo a reformulação da assistência aos pacientes, criação da oficina de artes dentro do Hospital de Alienados, atendimento médico ambulatorial e social, além de ações que visavam os cuidados extra-hospitalares e a não hospitalização, porém, o governo do Estado não aceitara a movimentação contraditória ao modelo hegemônico da época e exonera o Dr. João Machado(3).

Utilizando sua influência e persistência, Dr. João Machado prossegue em sua luta pela reestruturação da psiquiatria potiguar, organizando eventos científicos, capacitações de profissionais, conscientização da população sobre o novo modelo assistencial, inclusão da disciplina de Psiquiatria na grade curricular do curso de Serviço Social, denúncias dos maus-tratos aos doentes e, por fim, em 1957, a construção do Hospital Colônia de Psicopatas, posteriormente renomeado de Hospital João Machado, em homenagem ao seu idealizador ${ }^{(3,6)}$.

O Hospital João Machado recebe os pacientes do Hospital de Alienados e inicia suas atividades, diante do novo modelo de reintegração social e reabilitação daqueles doentes, a psiquiatria potiguar se renova, até o falecimento do Dr. 
João Machado, em 1965, o que trouxe profundas transformações. Progressivamente, o cenário do Lazareto foi reconstruído, devido ao descaso e à falta de compromisso governamental em manter a colônia funcionando adequadamente, sendo os anos vindouros de depreciação ${ }^{(3,8)}$.

Entre os anos de 1980 e 1990, surge em Natal um movimento de reforma psiquiátrica, formado por profissionais do setor, engajados na então criada Secretaria de Saúde do Município, que, em 1987, incorpora psicólogos em seu quadro funcional. Estes, juntamente com os enfermeiros, médicos e assistentes sociais, encabeçam a luta contra hegemônica, traduzida no projeto Proposta de Reorganização da Atenção em Saúde Mental no Município de Natal ${ }^{(3-4)}$.

$\mathrm{Na}$ perspectiva do processo histórico de implantação da reforma psiquiátrica no Estado do Rio Grande do Norte, é importante destacar a experiência inaugural do novo modelo de atenção à saúde mental de 1992, implementado pela Secretaria Municipal de Saúde de NatalRN, por meio da criação de Núcleos e Centros de Atenção Psicossocial, autorizados pelo Ministério da Saúde, pela Portaria 224 de 29 de janeiro de 1992, constituindo-se de unidades de saúde assistenciais locais (CAPS) e regionais (NAPS) direcionadas aos clientes com transtornos mentais ${ }^{(8)}$.

Em outubro de 1992, o movimento em prol da luta antimanicomial ganha força após a $1^{\text {a }}$ Conferência Municipal de Saúde Mental de Natal-RN, em parceria com a Universidade Federal do Rio Grande do Norte, contando com a participação de quinhentos profissionais da área e o apoio do Ministério da Saúde, sendo organizada formalmente nesse mesmo ano, por meio das resoluções da 2a Conferência Nacional de Saúde Mental, que preconizou a formação de uma rede de atenção integral em saúde mental em busca da criação de serviços substitutivos dos hospitais psiquiátricos ${ }^{(7)}$.

Em novembro de 1992, foi lançada a proposta de reorganização da atenção à saúde mental no município de Natal-RN, por meio do sistema de atendimento integrado, na qual a saúde mental passava a ser assistida em níveis de atenção primária, secundária e terciária, complementada pelas policlínicas especializadas, centros de atendimento 24 horas, disponibilidade de leitos psiquiátricos em hospitais gerais, centros de atendimento psicossocial e abrigos protegidos ${ }^{(3,7)}$.

Outros eventos foram de extrema importância para a reforma psiquiátrica em Natal-RN como o 1ํㅗeminário de Profissionais de Saúde Mental, em 1988, e a implantação do Programa de Saúde Mental no Centro de Saúde de Pirangi, em 1994.

Em 1994, acontece a implantação do primeiro NAPS em Natal-RN, localizado na região leste da cidade, com capacidade para atender sessenta usuários, porém, a demanda superou a oferta do serviço, o que perdura nos dias atuais, resultando na criação de uma lista de espera para ingresso de novos usuários, gerando dificuldades locais quando da necessidade de encaminhar pacientes à unidade de referência em saúde mental ${ }^{(3,8)}$.

No processo de desenvolvimento da reforma psiquiátrica brasileira, o Rio Grande do Norte se antecipou à lei $10.216 / 2001$, por meio da lei estadual 6.758, de 4 de janeiro de 1995, que proíbe a construção e ampliação de hospitais psiquiátricos no estado, ressalvadas as obras que tinham como finalidade proporcionar melhorias, modernização e adequações das estruturas e instalações, permitidas somente pela Secretaria de Saúde Municipal ${ }^{(3,9)}$.

Em 1995, foram implantados o NAPS e CAPS na região oeste de Natal-RN, este último sendo destinado ao atendimento exclusivo de dependentes químicos e alcoolistas. No ano de 1997, foi criado o Hospital-Dia (HD), que, durante quase dez anos, realizou uma média de 1.800 atendimentos. Entre os objetivos do HD, destacavam-se o de melhorar a transição entre o regime de internação e o lar, prevenir recaídas durante o tratamento e evitar a hospitalização completa. Nessa modalidade de acompanhamento, os indivíduos eram encorajados a retornar ao convívio social com maior brevidade ${ }^{(8-9)}$.

Mesmo contribuindo imensamente com o fortalecimento das boas práticas em saúde mental, o HD é extinto na cidade de Natal-RN no ano de 2006, sem aparente explicação política ou econômica para o encerramento de suas atividades, repercutindo drasticamente na vida dos usuários, familiares e profissionais da psiquiatria potiguar. Atualmente, o espaço físico do HD deu origem à Unidade de Desintoxicação (UD), destinada à crescente incidência e prevalência de 
usuários de álcool e drogas, até então inexistente no sistema público de saúde em Natal. A Unidade de Tratamento de Álcool e Drogas (UTAD), no Hospital Universitário Onofre Lopes, é outro serviço que desenvolve o mesmo trabalho no estado do Rio Grande do Norte ${ }^{(9)}$.

Os dados do NAPS leste e oeste de NatalRN, entre os anos de 1994 e 2001, demonstram significativos avanços na redução do número de internamentos psiquiátricos tradicionais. Anteriormente à criação do NAPS, $50 \%$ dos novos usuários não precisaram de internamento, mas, após a sua criação, observa-se que $82 \%$ não precisaram se internar.

O Rio Grande do Norte ocupa a oitava colocação no ranking da cobertura CAPS/100.000 habitantes por Unidade da Federação. O Governo do Estado e a Secretaria de Saúde Pública (SESAP) têm disponíveis 572 leitos psiquiátricos ${ }^{(10)}$.

Apesar dos números serem animadores, a efetivação da reforma psiquiátrica em NatalRN está em processo de construção, perceptível nas dificuldades que se observam, como o acesso restrito às unidades primárias, secundárias e terciárias, tempo prolongado de tratamento, demanda reprimida, ausência de efetivas políticas de reinserção social, estigma e preconceitos ${ }^{(8)}$.

Os internamentos psiquiátricos após a criação do NAPS, segundo os profissionais desses núcleos, se deram, em sua maioria, pela falta de recursos terapêuticos, como leitos em hospitais gerais ou em centros de atendimentos 24 horas, para acolhimento nos momentos de crises dos clientes $^{(3)}$.

O processo de Reforma Psiquiátrica no Rio Grande do Norte evolui em meio aos problemas ocasionados pelos conflitos de interesses políticos, diversidade de opinião entre os profissionais da saúde, a manutenção da cultura manicomial, sérios entraves financeiros e institucionais ${ }^{(10)}$.

A integração da Unidade de Saúde da Família e os serviços de saúde mental constituem-se em outra importante ferramenta de efetivação da Reforma Psiquiátrica no Rio Grande do Norte. Entretanto, o modelo biomédico, a supervalorização do uso de psicotrópicos, a fragmentação da saúde, a má definição de recursos financeiros, a insatisfatória ampliação e capacitação profissional e a ausência de mecanismos avaliativos dos serviços emperram o processo de mudanças no âmbito das práticas em saúde mental $^{(11)}$.

A existência de serviços substitutivos das instituições manicomiais não representa a efetivação da Reforma Psiquiátrica potiguar, destarte, configuram simplesmente as ferramentas que a nova proposta requer, que, numa perspectiva prática, não tem qualquer valor sem recursos humanos capacitados e comprometidos com as mudanças assistenciais.

\section{A enfermagem e a saúde mental: as faces do cuidado}

Os serviços especializados no atendimento aos portadores de transtornos mentais, na cidade de Natal-RN possuem em sua maioria, uma equipe de enfermagem atuante e compromissada em efetivar as propostas da reforma psiquiátrica no cotidiano do cuidar, porém, sem autonomia e com pouca cientificidade ${ }^{(3)}$. Possivelmente, evidencia-se esta realidade nas poucas publicações científicas apresentadas na figura 1 .

A enfermagem possui amarras que estão arraigadas na origem da profissão quando da sua inserção em psiquiatria; a sistematização da assistência, as teorias, a cientificidade discutível, enfraquecem as ações do enfermeiro na saúde mental a favor de sua autonomia e especificidade prática e científica, contribuindo com uma crise visível nos serviços prestados aos enfermos mentais no Rio Grande do Norte, especialmente em Natal-RN ${ }^{(3,12-13)}$.

Os enfermeiros da saúde mental podem estar repetindo os erros cometidos nos primórdios da enfermagem psiquiátrica, ao se deterem em assistir as demandas externas e culminarem por sucumbir suas potencialidades em cuidar, retrocedendo na construção e reafirmação da enfermagem como ciência ${ }^{(13)}$.

Os pontos positivos, e provavelmente os mais importantes, são que os enfermeiros da saúde mental de Natal-RN possuem o compromisso e o interesse em mudar o contexto do cuidar, se relacionam bem com a clientela e seus familiares, numa dualidade de confiança e carinho, o que parece ser um passo gigante em direção à humanização da assistência ${ }^{(3,8,14)}$.

O processo de trabalho dos enfermeiros em saúde mental está condicionado aos poucos incentivos e oportunidades de fortalecimento da 
prática assistencial e na ausência de programas de educação continuada na área ${ }^{(3,5)}$.

O papel social, o científico e o humanístico do curso de enfermagem inclinam para a formação profissional voltada ao fortalecimento da implementação da Reforma Psiquiátrica no Rio Grande do Norte, a percepção dos alunos são de engajamento à reordenação das práticas assistenciais $^{(10)}$.

A revisão integrativa aqui apresentada fortalece a discussão acerca do processo de reforma psiquiátrica em âmbito regionalizado, entretanto, se configura em importante fonte de debates sobre a reformulação da assistência de enfermagem em saúde mental, consubstanciando de evidências as informações que compõem este estudo.

\section{Considerações Finais}

A reforma psiquiátrica não pode se restringir à promoção da desinstitucionalização do hospital psiquiátrico, destarte, deverá criar novos centros e núcleos de apoio psicossocial, com consequente aumento dos usuários inscritos, reintegrando-os à sociedade e reabilitando-os ao convívio humano solidário, não permitindo que se construam prisões domiciliares, ou a segregação imposta pelos atos estigmatizantes, mas uma verdadeira reformulação diária na assistência proporcionada pelas instituições antimanicomiais e, principalmente, no núcleo social fundamental, a família destes pacientes.

A descontinuidade das ações propostas pela reforma psiquiátrica está intimamente relacionada ao compromisso político e social, o que faz emergir a percepção de que, no contexto histórico e atual, a assistência ao portador de transtornos mentais não se constitui numa prioridade de governo, nem da sociedade, e sim numa necessidade latente da família de extrair do seu convívio o paciente psiquiátrico, por medo, inabilidade no cuidado ou simplesmente estigma. Por outro lado, os gestores públicos, descompromissados em transformar o cuidado a essa clientela.

A assistência ao paciente portador de sofrimento psíquico em Natal-RN é ofertada por uma rede de serviço organizada, formada pelas instituições manicomiais, hospitais gerais com leitos exclusivos a essa clientela, centros e núcleos de assistência psicossocial e apoio da Estratégia Saúde da Família, tendo diminuído consideravelmente as internações em hospitais psiquiátricos, mas ainda de forma não muito animadora.

A articulação entre os núcleos e centros de atenção psicossociais e a atenção básica de saúde, deve ser fortalecida por políticas públicas mais efetivas, maior sensibilização e preparo técnico e científico dos profissionais dessas áreas, além de estratégias de conscientização e motivação a coparticipação social nesse processo.

A necessidade de maior capacitação dos enfermeiros em saúde mental alicerça-se na exigência desse profissional em favorecer a integração de ações que promovam a efetivação das transformações práticas, saberes e valores culturais, impregnados no cuidado cotidiano aos clientes e seus familiares, contribuindo para a otimização das relações interpessoais, intermediando impasses, tensões e conflitos, investindo seus esforços na reintegração e reabilitação social dessas pessoas historicamente vitimadas pelos maus-tratos.

\section{Referências}

1. Secretaria Municipal de Saúde do Município de Natal (BR). Propostas de reorganização da atenção em saúde mental no município de NatalRN. Natal: SMS; 1992.

2. Polit DF, Beck CT, Hungler BP. Fundamentos de pesquisa em enfermagem. Porto Alegre: Artmed; 2004.152 p.

3. Dantas RC. Histórias de vidas de usuários de psicofármacos: o desafio do cuidar para a enfermagem. [Dissertação de Mestrado em Enfermagem Saúde Mental]. Natal: Departamento de Enfermagem da Universidade Federal do Rio Grande do Norte; 2009. 122 p.

4. Miranda FAN, Simpson CA, Fernandes RL, Silva MB, Sabino MGG. Representações sociais e o papel terapêutico dos acadêmicos de enfermagem. Rev Bras Enferm. 2009;62(5):663-9.

5. Silva TC, Kirschbaum DIR. A construção do saber em enfermagem psiquiátrica: Uma abordagem histórico-crítica. SMAD. Rev. Eletrônica Saúde Mental Álcool Drog. (Ed. port.). 2010;6(esp):409-38.

6. Azevedo JR. Diálogos da alma: uma outra história da loucura. [Dissertação de Mestrado em Educação]. Natal: Programa de Pós-graduação 
em Ciências Sociais da Universidade Federal do Rio Grande do Norte; 2006. 184 p.

7. Caldas GHO, Macedo MRC. Assistência à Saúde Mental em Natal-RN: O Confronto de Dois Modelos. Psychiatry on line Brasil. 2008;13:298-65.

8. Paiva IL, Yamamoto OH. Em defesa da reforma psiquiátrica: por um amanhã que há de nascer sem pedir licença. História, Ciências e Saúde. 2007;14(2):549-69.

9. Pessoa JJM, Medeiros VKN, Miranda FAN. Extinção de um serviço psiquiátrico intermediário e as repercussões na atenção à saúde mental. Cienc Cuid Saude. 2011; 10(3):578-84.

10. Miranda FAN, Clementino FS, Santos RCA, Silva MB, Costa TS. Percepção de alunos de graduação em enfermagem sobre o processo de reforma psiquiátrica no Brasil. Rev Enferm UERJ. 2010;18(2):235-40.

11. Dimenstein M, Severo AK, Brito M, Pimenta AL, Medeiros V, Bezerra E. O apoio matricial em unidades de saúde da família: experimentando inovações em saúde mental. Saúde Soc. 2009;18(1):63-74.

12. Bezerra CG, Dimenstein M. O fenômeno da reinternação: um desafio à reforma psiquiátrica. Mental. 2011;(16):417-42.

13. Vinha IR. Escenario de la atención en salud mental/uso de sustancias psicoactivas en la Región Sanitaria de Piracicaba, São Paulo, Brasil. SMAD. Rev. Eletrônica Saúde Mental Álcool Drog. (Ed. port.) 2011;7:25-31.

14. Santos YF. O ambulatório de Saúde Mental no contexto da Reforma Psiquiátrica em Natal-RN. [Dissertação de Mestrado em Psicologia]. Natal: Programa de Pós-graduação em Psicologia da Universidade Federal do Rio Grande do Norte; 2007. 169 p. 